\title{
COMPOSICIÓN FLORÍSTICA DE CUATRO HÁBITATS EN EL RANCHO LAS PAPAS DE ARRIBA, MUNICIPIO DE OJUELOS DE JALISCO, JALISCO, MÉXICO
}

\author{
Mollie Harker ${ }^{1}$, Luz Adriana Garcia Rubio ${ }^{1}$ y Mónica E. Riojas-López ${ }^{2}$ \\ ${ }^{1}$ Universidad de Guadalajara, Departamento de Botánica y Zoología, \\ Centro Universitario de Ciencias Biológicas y Agropecuarias, \\ Apdo. postal 1-139, 45101 Zapopan, Jalisco, México.
}

${ }^{2}$ Universidad de Guadalajara, Departamento de Ecología, Centro Universitario de Ciencias Biológicas y Agropecuarias, km. 15.5 carr. Nogales, 45100 Zapopan, Jalisco, México.

\section{RESUMEN}

En el rancho Las Papas de Arriba, municipio de Ojuelos de Jalisco, Jalisco se estudió la composición florística y las formas biológicas de cuatro hábitats: matorral xerófilo crasicaule, pastizal, cultivo maduro de nopal tunero (Opuntia spp.) y cultivo joven de nopal tunero, con el objetivo de dar cuenta de la riqueza de este sitio y comparar la fisonomía de los diferentes ambientes. El catálogo consta de 356 especies y taxa subespecíficos, las que representan 73 familias y 230 géneros de plantas vasculares. Las familias con mayor número de géneros y especies son Asteraceae $(48,76)$, Poaceae $(29,46)$, Fabaceae $(13,19)$ y Cactaceae $(6,19)$ y los géneros con mayor riqueza Opuntia (10), Euphorbia (9), Solanum (7), Pseudognaphalium (6), Bouteloua (6), Ipomoea (6) y Muhlenbergia (6). Del total de especies registradas, $36 \%$ son endémicas de México y $4 \%$ son introducidas; nueve no se conocían antes de Jalisco y cinco tienen problemas de conservación. Las formas de vida mejor representadas son las plantas herbáceas con 285 especies, anuales 108 y perennes 177 (en conjunto alcanzando $80 \%$ del total). El matorral muestra la mayor diversidad alfa con 223 especies (62.6\% del total) y es el hábitat más complejo en fisonomía conteniendo siete formas de vida, así como el que presenta el mayor número de elementos exclusivos. El pastizal contiene 119 especies (33.4\% del total), el cultivo maduro de nopal $138(38.8 \%)$ y el cultivo joven de nopal 132 (37.1\%). Estos dos últimos hábitats fueron los más similares en cuanto a la composición florística compartiendo $35 \%$ de las especies.

Palabras clave: cultivo de nopal, flora, Jalisco, matorral xerófilo, México, pastizal, similitud florística. 


\section{ABSTRACT}

Floristics and plant physionomy of four habitats were studied in the Papas de Arriba ranch, Ojuelos de Jalisco, Jalisco: xerophilous scrub, natural grassland, an established orchard of prickly pear (Opuntia spp.) and other recently planted fields of prickly pear. The list presented includes 356 species and subspecific entities, representing 73 families and 230 genera of vascular plants. The families with most genera and species are Asteraceae (48/76), Poaceae (29/46), Fabaceae (13/19) and Cactaceae (6/19), while the richest genera are Opuntia (10), Euphorbia (9), Solanum (7), Pseudognaphalium (6), Bouteloua (6), Ipomoea (6) and Muhlenbergia (6). Thirty six percent of the species are endemic to Mexico and only $4 \%$ are introduced. Included in the list are 9 species not reported before from Jalisco and 5 species of threatened plants. Herbs are the dominant guild including 108 annuals and 177 perennials, together 285 species ( $80 \%$ of the flora). The xerophilous scrub presents the greatest alpha diversity with 223 species $(62.6 \%$ of the total), while there are $119(33.4 \%)$ in the grassland, $138(38.8 \%)$ in the established orchard and 132 (37.1\%) in the recently planted fields. The xerophilous scrub also has the greatest number of exclusive species and is more complex with 7 plant life forms represented there. The Opuntia orchard and recently planted fields are most similar floristically sharing $35 \%$ of the species.

Key words: flora, floristic similarity, grassland, Jalisco, Mexico, prickly pear orchards, xerophilous scrub.

\section{INTRODUCCIÓN}

El municipio de Ojuelos de Jalisco, Jalisco, se ubica en el occidente de la provincia florística de la Altiplanicie Mexicana, en el extremo noreste del estado y forma parte de la subprovincia fisiográfica Llanuras de Ojuelos-Aguascalientes (Anónimo, 1981). Su clima es semiárido y el paisaje está conformado por grandes extensiones de pastizales semidesérticos que forman parte del continuo de los pastizales que se distribuyen desde el centro-oeste de Norteamérica hasta el noreste de Jalisco y un poco más hacia el sur (Rzedowski, 1978). Éstos, junto con diferentes tipos de matorral xerófilo, son los elementos dominantes del paisaje.

En el noreste de Jalisco desde la ocupación española, hace aproximadamente 450 años, los matorrales xerófilos y los pastizales han sido utilizados con fines ganaderos, mayormente para la cría de ovinos y, en menor escala, bovinos (Riojas-López y Mellink, 2005). Esta actividad reduce la cobertura vegetal y en consecuencia, afecta la diversidad florística y estructura de la vegetación (Noss, 1994). Durante los últimos 100 años, el impacto del ganado y la agricultura sobre estos ecosistemas semidesérticos ha aumentado drásticamente (Challenger, 1998). Uno de los aprovecha- 
mientos importantes de la tierra son también las plantaciones comerciales de nopal para la producción de tuna. Tan sólo en el municipio de Ojuelos de Jalisco de 1990 a 2000, la superficie así utilizada aumentó de 1900 a 2600 ha (F. Torres, com. pers.).

El conocimiento que actualmente se tiene sobre la flora y vegetación de estos pastizales y matorrales xerófilos es incompleto (McVaugh, 1972; Curiel, 1998) y se encuentra fraccionado en trabajos de diferente índole (Vargas et al., 2002; Garcia, 2003; Garcia et al, 2004). Los únicos catálogos florísticos que reúnen información sobre la subprovincia de las Llanuras en Jalisco en particular son los de Santana et al. (1987), Arreola $(1990,1996)$ y Harker et al. (2005).

El rancho Las Papas de Arriba, municipio de Ojuelos de Jalisco, Jalisco, México, es una pequeña propiedad, cuyos dueños apoyan la investigación biológica. El presente trabajo forma parte de un proyecto más amplio encaminado a describir la biodiversidad de la región, en el cual el rancho ha sido un punto de monitoreo de 1999 a 2003. Este estudio tiene como objetivo elaborar un catálogo de plantas vasculares y comparar la diversidad florística y fisonomía de cuatro ambientes distintos en el rancho Las Papas de Arriba. Los hábitats estudiados fueron matorral xerófilo crasicaule, pastizal, plantación comercial madura de nopal tunero y plantación comercial joven de nopal tunero.

\section{ÁREA DE ESTUDIO}

El rancho Las Papas de Arriba se ubica al noreste del estado de Jalisco en el municipio de Ojuelos de Jalisco (entre $21^{\circ} 43.30^{\prime}$ y $21^{\circ} 43.77^{\prime} \mathrm{N}, 101^{\circ} 39.48^{\prime}$ y $101^{\circ} 43.42^{\prime}$ O), a una altitud promedio de $2260 \mathrm{~m}$, con una superficie de 250 ha. (Fig. 1)

Según la clasificación de Köppen, el clima es semiseco-templado (BSk $)_{1}$ (García, 1973), con una precipitación media anual entre 300 y $500 \mathrm{~mm}$, la mayor parte de la cual se recibe entre junio y septiembre, con algunas lluvias aisladas de diciembre a febrero. Pueden presentarse hasta cinco días con granizadas al año, en julio y agosto. La temperatura promedio anual varía entre $16^{\circ}$ y $18^{\circ} \mathrm{C}$, con las máximas en abril y las mínimas en enero. Entre noviembre y abril se presentan entre 0 y 10 días con heladas. Los vientos dominantes soplan de noreste a suroeste (Anónimo, 1981). Los tipos de suelo más comunes en el municipio son xerosol y feozem háplicos, con una profundidad promedio de $40 \mathrm{~cm}$ y textura arenoso-arcillosa. El $\mathrm{pH}$ varía de 5 a 7 y el contenido de materia orgánica es bajo (1 a 3\%). Una capa de tepetate rica en sílice (fragipan) cerca de la superficie dirige el escurrimiento hacia lagunas endorreicas, charcos y arroyos de temporal (Anónimo, 1981). 


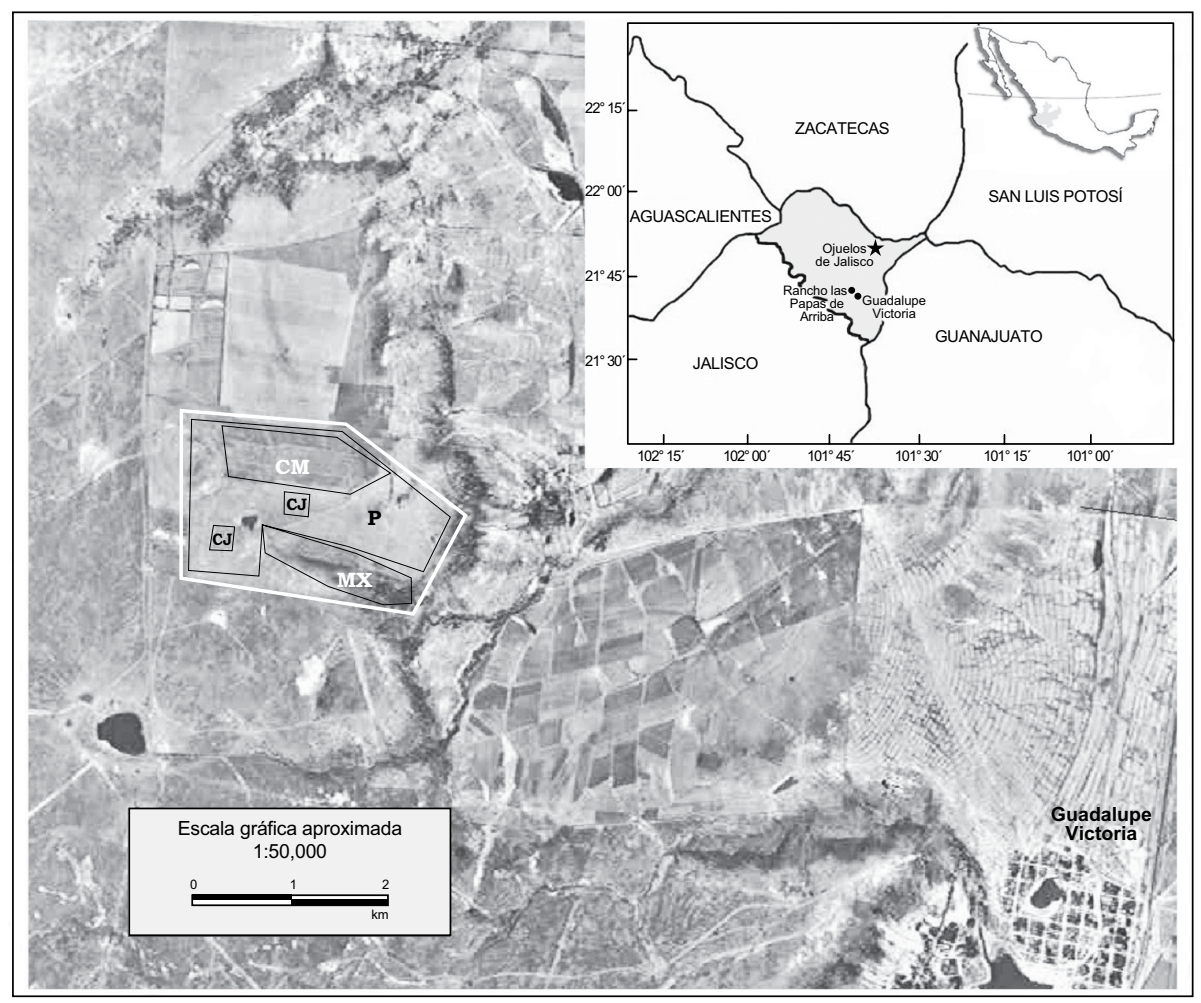

Fig. 1. Ubicación del área de estudio y los sitios de recolecta en el rancho Las Papas de Arriba, municipio de Ojuelos de Jalisco, Jalisco, México: matorral xerófilo crasicaule (MX), pastizal (P), cultivo maduro de nopal tunero (CM), cultivo joven de nopal tunero (CJ). (Fotografía aérea INEGI, 1991)

En el rancho se encuentran dos de las topoformas más representativas de las Llanuras: 1) una meseta que abarca la mayor extensión (215 ha) con una inclinación de aproximadamente $5 \%$, donde el suelo tiene una profundidad de 15 a $40 \mathrm{~cm}$, debajo del cual hay una capa de fragipan; 2) una cañada que delimita el extremo sur del rancho (35 ha), con sustrato rocoso expuesto de origen ígneo. La cañada se extiende de oeste a este, mide aproximadamente $600 \mathrm{~m}$ de largo y la profundidad varía de 2 a $30 \mathrm{~m}$. En su fondo corre un arroyo de temporal que alcanza hasta $0.5 \mathrm{~m}$ de profundidad en la zona de pozas, algunas de las cuales permanecen con agua todo el año. Todo el rancho se utiliza como agostadero, y durante el estudio lo pastoreaban ca. 400 cabezas de ganado ovino. 


\section{MÉTODOS}

Este trabajo abarcó los cuatro hábitats principales del rancho, uno localizado en la cañada y tres en la meseta (Fig. 1): 1) matorral xerófilo crasicaule (MX) (Rzedowski y McVaugh, 1966; Rzedowski, 1978); 2) pastizal (P); 3) cultivo maduro de nopal tunero (CM) y 4) cultivo joven de nopal tunero (CJ). El MX (35 ha) se restringe a la cañada y su extremo oeste está dominado por cactáceas, otros arbustos como Dasylirion, Perymenium y Jatropha y plantas herbáceas como Salvia, Plantago y Cyperus; en su parte este prevalecen árboles de Quercus y arbustos de Dalea, Montanoa y Stevia. Dada la historia de manejo del rancho Las Papas, este matorral, como otros de la región, ha sufrido cambios en su composición debido a actividades antropogénicas, con una presencia importante de elementos de vegetación secundaria (Rzedowski, 1960). Sin embargo, con base en las especies dominantes es similar al matorral xerófilo crasicaule (Rzedowski y McVaugh, 1966; Rzedowski, 1978). El P (127 ha) está caracterizado por gramíneas nativas, incluyendo especies de Bouteloua y Muhlenbergia y otras plantas herbáceas como Bouchetia y Nemastylis. En este hábitat se encuentra un bordo (represa artificial rústica donde abreva el ganado). Las plantaciones de nopal tunero en este rancho son agrosistemas perennes y no mecanizados. En el presente trabajo se denominaron "cultivos", ya que así las llaman los productores de la región. El CM es una plantación ( 80 ha) que se estableció en 1986 con los cultivares de Opuntia megacantha cv Torreoja, O. megacantha cv Picochulo y Opuntia albicarpa cv Burrona. Las pencas madre de nopal se plantaron cada $3 \mathrm{~m}$ a lo largo de surcos separados $5 \mathrm{~m}$ uno del otro y se mantienen en la actualidad como arbustos de 0.80 a $2 \mathrm{~m}$ de altura mediante podas de formación. El CJ estudiado corresponde a dos parcelas de 4 ha cada una, cuyo cultivo se inició en 1998 y 1999. El sitio en el que se establecieron anteriormente era parte del pastizal.

Entre febrero de 1999 y diciembre de 2000 se realizó una recolecta botánica intensiva mensual, además de otras efectuadas en octubre de 2004, así como en marzo y octubre de 2005. Éstas se hicieron conforme a las técnicas propuestas en Lot y Chiang (1986). Para cada ejemplar obtenido se anotó su forma de vida y abundancia relativa. Esta última se basó en una estimación cualitativa. Los especímenes debidamente determinados se depositaron en el herbario IBUG del Instituto de Botánica de la Universidad de Guadalajara y se enviaron duplicados a GUADA, IEB y SLPM. Los datos se capturaron en la base de datos VITEX-IBUG. Para la identificación de materiales botánicos se usó la siguiente literatura: McVaugh (1983, 1984, 1985, 1987, 1989, 1993 y 2001), González (1986), Cervantes (1992), Jones (1988), González et al. (2001) y Rzedowski et al. (2001). El catálogo se ordenó alfabéticamente en los 
niveles de familia, género y especie. Para las pteridofitas se siguió el sistema propuesto por Mickel (1992), para las Magnoliopsidas el de Cronquist (1981) y para las Liliopsidas el de Dahlgren et al. (1985). Los nombres de los autores de las especies se abreviaron de acuerdo con Villaseñor (2001). Asimismo, se agregó más información que se detalla en el inicio del catálogo florístico (Apéndice). En el caso de las especies consideradas en riesgo, se anotaron las categorías de protección respectivas según la NOM-ECOL-059-2001 (Anónimo, 2001) y el Libro Rojo de la IUCN (Walter y Gillett, 1998).

La descripción fisonómica de cada hábitat se basó en la presencia de las formas de vida, conforme a las siguientes categorías: herbácea anual, herbácea perenne (ambas incluyen a las herbáceas acuáticas), crasicaule globosa, arbustiva, arbórea, epífíta y parásita. Para la descripción de la riqueza florística se empleó el número total de especies presentes por hábitat. La comparación de la diversidad entre los diferentes ambientes se hizo mediante un análisis de similitud, para lo que se usó el índice de Jaccard (Krebs, 1999), basado en la presencia-ausencia de las especies estudiadas en cada par de comunidades o hábitats.

\section{RESULTADOS Y DISCUSIÓN}

En el rancho Las Papas de Arriba se realizaron 656 recolectas de plantas como respaldo de 356 especies (Cuadro 1, Fig. 2 y Apéndice). La familia Asteraceae (48 géneros, 76 especies), tuvo la mayor riqueza en géneros y especies seguida de Poaceae $(29,46)$, Fabaceae $(13,19)$, Cactaceae $(6,19)$, Solanaceae $(7,17)$ y Euphorbiaceae $(3,11)$, familias que en conjunto conforman $52.5 \%$ del total. En regiones de clima semiárido, especialmente en matorrales xerófilos, las familias Asteraceae, Poaceae, Fabaceae y Cactaceae están bien representadas (Rzedowski, 1972, 1978). Este mismo patrón se presentó en el rancho. La gran diversidad de Asteraceae puede atribuirse a sus adaptaciones evolutivas como fertilidad alta, eficiencia en dispersión y plasticidad química (Villaseñor, 1993). Dentro de la misma familia y al igual que en otras zonas semiáridas de México (Rzedowski, 1972), en el área de estudio, la tribu Heliantheae fue mejor representada con 25 especies (33\%), mientras que el género Pseudognaphalium de la tribu Inuleae fue el más rico en especies (6). Otras plantas muy abundantes en todo el rancho fueron Aphanostephus ramosissimus var. ramosissimus, Dyssodia papposa, Heterosperma pinnatum, Isocoma hartwegii, Laennecia sophiifolia, Piqueria trinervia y Schkuhria spp. La segunda familia mejor representada fue Poaceae. Bouteloua gracilis, B. curtipendula, B. hirsuta, Buchloe 
Cuadro 1. Composición de la flora en el rancho Las Papas de Arriba, en términos de grandes grupos de plantas vasculares.

\begin{tabular}{lccc}
\hline \multicolumn{1}{c}{ Clase } & Familias & Géneros & Especies \\
\hline Filicopsida & 4 & 6 & 9 \\
Lycopodiopsida & 1 & 1 & 2 \\
Magnoliopsida & 52 & 170 & 266 \\
Liliopsida & 16 & 53 & 79 \\
Total & 73 & 230 & 356 \\
\hline
\end{tabular}

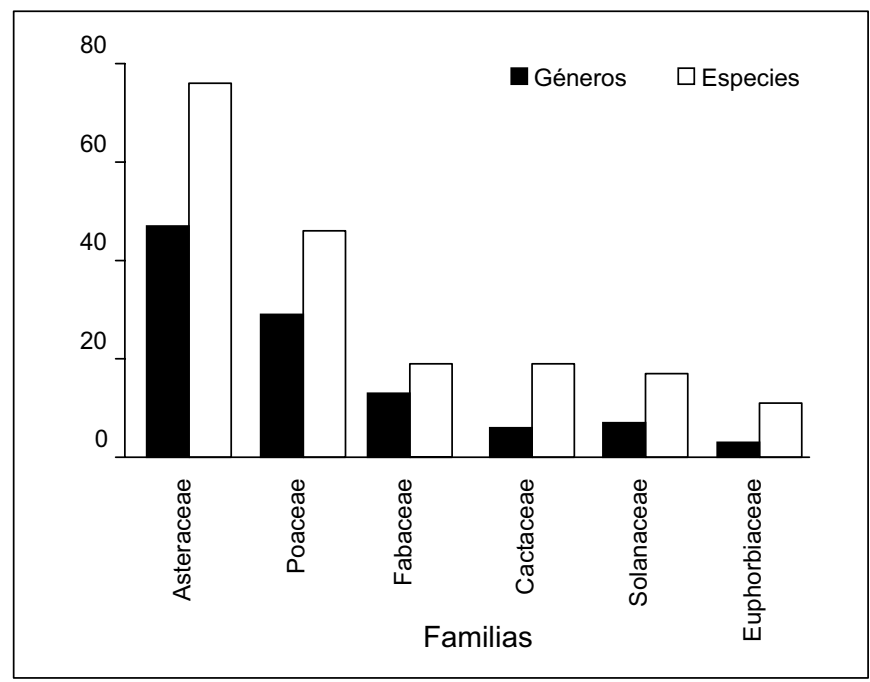

Fig. 2. Familias con mayor número de especies y géneros en la flora del rancho Las Papas de Arriba.

dactyloides, entre otras, son elementos de la franja continua de pastizales naturales que se extienden desde centro-oeste de Norteamérica hasta la Mesa Central de México (Rzedowski, 1975). Adicionalmente se registraron elementos endémicos de México, como Bouteloua scorpioides, Brachiaria meziana, Elyonurus barbiculmis y Muhlenbergia pubescens (Rzedowski et al., 2001).

De las familias encontradas, $35 \%$ estuvieron representadas por una especie. Los géneros más ricos, con al menos cinco taxones, fueron Opuntia (10), Euphorbia (9), Solanum (7), Pseudognaphalium (6), Bouteloua (6), Ipomoea (6), Muhlenbergia 
(6), Stevia (5), Physalis (5) y Cyperus (5). Algunas especies conocidas a partir de uno o pocos individuos se pueden considerar raras (Rabinowitz et al., 1986). En el rancho se encontraron en esta condición Bursera fagaroides, Calliandra humilis, Centaurium brachycalyx, Echeveria mucronata, Hybanthus verticillatus, Lopezia trichota, Mancoa mexicana, Microchloa kunthii, Nierembergia angustifolia, Phaseolus polymorphus, Phyla nodiflora, Prionosciadium thapsoides, Prunus serotina subsp. capuli, Salix humboldtiana, Stenandrium dulce, Tillandsia tortilis, Triodanis biflora y Zaluzania augusta.

La flora estudiada incluyó 121 especies y entidades subespecíficas endémicas de México (34\% del total). De éstos, 97 (27\%) son de la Mesa Central, algunos con distribución amplia desde la frontera con los Estados Unidos de América; por ejemplo, Baccharis sulcata cuyo límite meridional es la región de Ojuelos. Vargas et al. (1998) consideran a Physalis hastatula como endémica de un área restringida a Aguascalientes, Guanajuato y Jalisco, específicamente en los alrededores de Ojuelos. Entre otros elementos endémicos de México, Dasylirion acrotriche y Ferocactus histrix fueron abundantes en los hábitats rocosos de la cañada y en esta localidad no se les extraía para su aprovechamiento, como sucede en gran parte de la región.

En lo que se refiere a especies en riesgo, se encontraron Dasylirion acrotriche, que está considerada como amenazada y Ferocactus histrix como sujeta a protección especial (NOM-059-ECOL-2001). En cambio, otras plantas escasas, como Matelea decumbens, Nierembergia angustifolia y Physalis glutinosa están catalogadas como raras en México, según el Libro Rojo de la IUCN (Walter y Gillett, 1998).

Aunque no existe una flora completa publicada para Jalisco, en la contribución de Vargas et al. (2002), se reúne la bibliografía acerca de trabajos botánicos para la citada entidad. En el presente artículo se documentan por primera vez nueve especies para el estado, las que se listan a continuación: Ageratina petiolaris, Bahia schaffneri var. schaffneri, Chaetopappa ericoides, Melampodium strigosum, Pseudognaphalium conoideum (Asteraceae); Mancoa mexicana (Brassicaceae); Lobelia berlandieri var. seleriana (Campanulaceae); Spergularia mexicana (Caryophyllaceae); Tillaea aquatica (Crassulaceae); Fuertesimalva jacens (Malvaceae); Eriogonum wrightii ssp. wrightii (Polygonaceae); Prunus microphylla (Rosaceae) y Linaria canadensis (Scrophulariaceae). Estas plantas se conocen de otros ambientes similares fuera del estado, por lo que era de esperarse su presencia en el área estudiada.

El matorral xerófilo crasicaule (MX) cuenta con la mayor diversidad alfa y presentó más especies exclusivas (114). Igualmente, en su flora pudieron registrarse 
las siete formas de vida que se distinguen en este trabajo, las que están más ampliamente representadas por diferentes especies (Cuadro 2). Tal hábitat, como se mencionó arriba, se encuentra restringido a una cañada, donde la pendiente y el relieve modifican las condiciones de humedad, además de ser un mosaico de microambientes, lo que explica porqué el MX es el sitio más diverso y complejo fisonómicamente. Las plantas arbustivas (Asclepias linaria, Dasylirion acrotriche, Jatropha dioica, Opuntia spp.) y algunas crasicaules globosas (Ferocactus histrix y Stenocactus ochoterenanus) son abundantes en la parte menos profunda y más expuesta. La presencia y abundancia de dichas formas de vida definen la fisonomía de esta fase del MX. La porción del MX con condiciones intermedias se caracteriza por otros elementos arbustivos comunes como Mimosa aculeaticarpa, Opuntia joconoste, Perymenium mendezii var. mendezii y Stevia salicifolia var. salicifolia. En la zona de mayor profundidad y humedad, la fisonomía está determinada por los arbustos Pittocaulon praecox, Dalea bicolor var. bicolor y Montanoa leucantha ssp. leucantha, así como los árboles ramosos bajos de Quercus eduardi, Q. grisea, y $Q$. potosina. Durante la temporada de lluvia las especies herbáceas codominan el paisaje con las arbustivas en la parte alta y media del MX. Igualmente en los meses de lluvia, el arroyo que corre por el fondo de la cañada favorece el establecimiento de plantas semiacuáticas en sus orillas, como Bulbostylis juncoides, Centaurium spp., Juncus microcephalus, Lobelia berlandieri var. seleriana y Nama origanifolium. En las charcas permanentes de la cañada se colectaron Callitriche heterophylla, Heteranthera rotundifolia y Potamogeton diversifolius.

El pastizal (P) es el hábitat de menor diversidad alfa, en el cual se registra la presencia de especies de cinco de las siete formas de vida (Cuadro 2). La fisonomía del $\mathrm{P}$ está dada principalmente por plantas herbáceas del género Bouteloua ( $B$. gracilis, B. simplex, B. scorpioides) y algunas otras como Aristida divaricata, Lycurus phleoides, Muhlenbergia repens y $M$. rigida. A pesar de que el $\mathrm{P}$ evidencia sobrepastoreo, $75 \%$ de las especies de zacates son perennes nativas, que aparentemente tienen la capacidad de soportar un buen grado de presión por uso pecuario (Riojas-López y Mellink, 2005). Los componentes herbáceos perennes de porte bajo, como Arenaria bourgaei, Bouchetia erecta, Euphorbia spp. y Evolvulus sericeus también son abundantes en este hábitat. Durante la época de lluvia, las depresiones del pastizal acumulan agua que favorece el crecimiento de algunas plantas acuáticas y semiacuáticas. En esas hondonadas se colectaron Marsilea mollis y Lilaea scilloides, junto con otros componentes menos comunes, como Helenium mexicanum y Eleocharis acicularis. Las especies arbóreas registradas en el P fueron 
Cuadro 2. Posparticipación cuantitativa de las diferentes formas de vida en los hábitats en el rancho Las Papas de Arriba. Los números entre paréntesis corresponden a las especies exclusivas de cada uno de los cuatro ambientes estudiados.

\begin{tabular}{lcccc}
\hline Formas de vida & $\begin{array}{c}\text { Matorral xerófilo } \\
\text { crasicaule }\end{array}$ & Pastizal & $\begin{array}{c}\text { Cultivo maduro } \\
\text { de nopal }\end{array}$ & $\begin{array}{c}\text { Cultivo joven } \\
\text { de nopal }\end{array}$ \\
\hline Herbácea anual & $57(27)$ & $39(11)$ & $37(9)$ & $52(17)$ \\
Herbácea perenne & $113(58)$ & $63(10)$ & $71(13)$ & $68(12)$ \\
Crasicaule globosa & $6(2)$ & $6(2)$ & $4(0)$ & $3(0)$ \\
Arbustiva & $33(16)$ & $7(0)$ & $24(8)$ & $8(1)$ \\
Arbórea & $10(7)$ & $4(1)$ & $2(1)$ & $1(0)$ \\
Epífita & $2(2)$ & - & - & - \\
Parásita & $2(2)$ & - & - & - \\
Total & $223(114)$ & $119(24)$ & $138(31)$ & $132(30)$ \\
\hline
\end{tabular}

individuos aislados de Opuntia chavena, O. hyptiacantha, Nicotiana glauca y Salix humboldtiana. Estas dos últimas crecían a la orilla del bordo que se encuentra en el pastizal. Ahí también, prácticamente a lo largo del año, se encontraron herbáceas semiacuáticas, como Bacopa procumbens, Cyperus spp., Petunia parviflora, Polygonum aviculare y Soliva anthemifolia.

En el cultivo maduro de nopal (CM) la fisonomía está dominada por los arbustos de nopal tunero, es el segundo hábitat en términos de cuantía de la diversidad alfa, y al igual que el pastizal muestra la existencia de cinco de las siete formas de vida, cuya representatividad siguió el mismo patrón que en el P.

De los hábitats de la meseta, el CM es el primero en número de especies arbustivas totales y exclusivas (Cuadro 2). Los cultivos perennes y sin mecanización permiten el establecimiento de una comunidad de plantas herbáceas y arbustivas (Paoletti et al., 1992), como es el caso del CM. En los microhábitats de estas nopaleras los cambios en la radiación solar y en la humedad son menos intensos que en los sitios abiertos y las plantas se encuentran menos expuestas al ramoneo por ganado. Algunas de las especies recolectadas que posiblemente se ven favorecidas por esta condición son Baccharis pteronioides, Buddleja spp., Ipomoea stans, Piqueria trinervia y Stevia salicifolia var. salicifolia, ya que son más abundantes cerca de las plantas de nopal. Entre los surcos, donde el impacto es mayor a causa del paso de la 
gente y del pastoreo, se recolectaron Bouteloua simplex, Cardionema ramosissima, Isocoma hartwegii, Laennecia sophiifolia y Lycurus phleoides. De las 60 especies arvenses conocidas para los cultivos de nopal en México (Villaseñor y Espinosa, 1998), en el CM se registraron 12. Otros elementos abundantes en este hábitat son Heterosperma pinnatum, Lepidium virginicum, Euphorbia serpyllifolia y Plantago mexicana. El uso de abono orgánico (estiércol de ovinos de la región) en el CM a mediano plazo podría influir y modificar la composición florística y la fisonomía del cultivo por el aporte posible de semillas contenidas en el abono.

El cultivo joven de nopal (CJ) es el tercer hábitat en cuanto al valor de la diversidad alfa, y también registró cinco de las siete formas de vida (Cuadro 2). El número de especies anuales es el más alto para los hábitats de la meseta, mientras que el de las plantas herbáceas perennes es comparable con el P y el CM. Las labores recientes para el establecimiento de este cultivo pudieron favorecer la proliferación de hierbas anuales, al igual que las que desarrollan bulbos subterráneos, como representantes de Calochortus, Milla, Nemastylis, Oxalis, Sisyrinchium y Viola, que también se encontraron en el P. Otras especies abundantes en el CJ, pero no en el P y de las que posiblemente se propició su establecimiento por el disturbio agrícola, son Amaranthus hybridus, Bidens ferulifolia, Brassica campestris, Chenopodium graveolens, Dyssodia papposa y Heterosperma pinnatum. Si se compara la superficie que ocupa este cultivo (4 ha) con la de las otras entidades muestreadas, la riqueza de especies es considerable, en función principalmente del aporte de plantas herbáceas anuales (Cuadro 2).

No obstante que los hábitats estudiados son contiguos, la similitud florística entre ellos es relativamente baja (Cuadro 3). Los más parecidos entre sí son los dos cultivos de nopal (0.35), y luego el CJ con el $\mathrm{P}$, circunstancia que podría deberse al establecimiento relativamente reciente del $\mathrm{CJ}$ en una superficie donde antes prosperaba un pastizal. De las especies recolectadas $54 \%$ se encontraron en sólo un hábitat, hecho que se explica por las características particulares de cada uno, el uso que se les da y el tiempo de establecimiento en el caso de las plantaciones de nopal.

Gran parte de los matorrales xerófilos de la Mesa Central están compuestos de vegetación secundaria, producto de la modificación antropógena (Rzedowski, 1960; Riojas-López y Mellink, 2005), lo que hace difícil una comparación entre ellos. El cuadro 4 compara la riqueza florística del rancho con la revelada por otros estudios para comunidades de las zonas semiáridas en la Mesa del Centro. Los sitios con los que se encontró el número mayor de especies compartidas son los municipios de Encarnación de Díaz y Lagos de Moreno, lo que se atribuye a que gran parte 
Cuadro 3. Similitud florística entre los cuatro hábitats estudiados en el rancho Las Papas de Arriba determinada mediante el índice de Jaccard.

\begin{tabular}{|c|c|c|c|c|}
\hline & 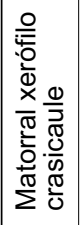 & $\begin{array}{l}\overline{\mathbb{N}} \\
\stackrel{N}{N} \\
\mathbb{N} \\
\mathbb{0}\end{array}$ & 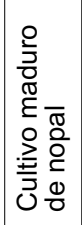 & 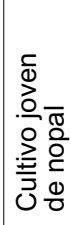 \\
\hline \multicolumn{5}{|l|}{ Matorral xerófilo crasicaule } \\
\hline Pastizal & 0.20 & & & \\
\hline Cultivo maduro de nopal & 0.25 & 0.27 & & \\
\hline Cultivo joven de nopal & 0.22 & 0.34 & 0.35 & \\
\hline
\end{tabular}

de la superficie de estas entidades esté incluida en la misma subprovincia fisiográfica y tenga condiciones ambientales similares. La siguiente localidad con la que se comparten más especies es la Sierra Monte Grande, S.L.P., lo que podría explicarse por la naturaleza del sustrato de la meseta del rancho, donde se encuentran tres de los cuatro hábitat estudiados, que es similar al de extensas planicies de que conforman el Altiplano Mexicano (Reyes-Agüero et al., 1996).

No obstante las actividades productivas que se realizan en el rancho Las $\mathrm{Pa}-$ pas, de forma general y considerando la superficie del área de trabajo $\left(2.5 \mathrm{~km}^{2}\right)$, éste posee una riqueza florística considerable si le compara con otros hábitats semiáridos de la Mesa Central (Cuadro 4). Con base en ello, la diversidad florística documentada en el presente trabajo bien podría reflejar una parte importante de las Llanuras de Ojuelos-Aguascalientes. De aquí que consideramos básico continuar no sólo con la exploración botánica en esta subprovincia fisiográfica, sino con estudios de ecología a fin de generar información básica, que sirva como referencia para ubicar las áreas, que por sus características, se les deberá considerar dentro de un plan de conservación biológica regional.

\section{AGRADECIMIENTOS}

Agradecemos a Fernando Torres Romo y su familia que generosamente prestaron su casa y el rancho para el trabajo de campo; a Pablo Carrillo Reyes quien 
Cuadro 4. Comparación de la riqueza florística documentada en el rancho Las Papas de Arriba, con las de otros sitios semiáridos de la Mesa Central. RLP: rancho Las Papas de Arriba.

\begin{tabular}{|c|c|c|c|c|}
\hline Sitio & $\begin{array}{l}\text { Extensión } \\
\left(\mathrm{km}^{2}\right)\end{array}$ & $\begin{array}{l}\text { Número de } \\
\text { especies }\end{array}$ & $\begin{array}{c}\text { Número de } \\
\text { especies en } \\
\text { común en el RPA }\end{array}$ & Referencia \\
\hline $\begin{array}{l}\text { Sierra Monte Grande, } \\
\text { S.L.P }\end{array}$ & 41.8 & 397 & 107 & $\begin{array}{l}\text { Reyes-Agüero et } \\
\text { al., } 1996\end{array}$ \\
\hline $\begin{array}{l}\text { Valle de San Luis } \\
\text { Potosí, S.L.P. }\end{array}$ & 2500 & 759 & 81 & Rzedowski, 1960 \\
\hline $\begin{array}{l}\text { Pastizales calcífilos } \\
\text { de Gto. }\end{array}$ & $\begin{array}{c}\text { no se } \\
\text { especifica }\end{array}$ & 282 & 61 & $\begin{array}{l}\text { Rzedowski y } \\
\text { Rzedowski, } 1995\end{array}$ \\
\hline $\begin{array}{l}\text { Sierra de la Paila, } \\
\text { Coah. }\end{array}$ & 1700 & 703 & 53 & Villarreal, 1994 \\
\hline $\begin{array}{l}\text { Bolsón Cuatro } \\
\text { Cienegas, Coah. }\end{array}$ & 2000 & 860 & 48 & Pinkava, 1984 \\
\hline $\begin{array}{l}\text { Mpios. Ojuelos y } \\
\text { Lagos de Moreno, Jal. }\end{array}$ & $\begin{array}{c}\text { no se } \\
\text { especifica }\end{array}$ & 363 & 122 & $\begin{array}{l}\text { Santana et al., } \\
1987\end{array}$ \\
\hline $\begin{array}{l}\text { Mpio. Encarnación de } \\
\text { Díaz, Jal. }\end{array}$ & ca. 250 & 266 & 122 & $\begin{array}{l}\text { Harker et al., } \\
2005\end{array}$ \\
\hline
\end{tabular}

ayudó en las colectas iniciales. Reconocemos la colaboración de los especialistas que brindaron su apoyo en la determinación de algunos ejemplares: Adriana González Durán, Raymundo Ramírez Delgadillo, J. Jacqueline Reynoso Dueñas, Miguel Ángel Macías Rodríguez, Aarón Rodríguez Contreras, José Luis Villalpando Prieto, Luz Maria González Villarreal, Ofelia Vargas Ponce, Hilda Julieta Arreola Nava, Rosa Elena Martínez González, Jerzy Rzedowski Rotter, Isidro Méndez Larios, Antonio Lot, Leandro S. Ramos, Socorro González Elizondo, José Luis Villaseñor Rios y Francisco Ramos R. Christian Briseño Avena ayudó en la edición de las figuras. El trabajo fue realizado en la Universidad de Guadalajara con apoyo económico de los proyectos CONACYT SIMORELOS (claves 19980306025 y 20000306006 ), y la Red de Nopal-SINAREFI (176-2003 y 2004), otorgados a Mónica E. Riojas-López. Este artículo derivó de la tesis de licenciatura de Luz Adriana Garcia. Agradecemos los comentarios de Aarón Rodríguez, Eric Mellink y tres revisores anónimos para mejorar el manuscrito. 


\section{LITERATURA CITADA}

Anónimo. 1981. Síntesis geográfica de Jalisco. Secretaría de Programación y Presupuesto. Coordinación General de los Servicios Nacionales de Estadística, Geografía e Informática. México, D.F. 306 pp.

Anónimo. 2001. Norma Oficial Mexicana NOM-059-ECOL-2001. Protección ambiental - especies nativas de México de flora y fauna silvestres - categorías de riesgo y especificaciones para su inclusión, exclusión o cambio - lista de especies en riesgo. Diario Oficial de la Federación. México, D.F. 83 pp.

Arreola, H. J. 1990. Inventario de las cactáceas de Jalisco y su distribución. Cact. Suc. Mex. 35(1): 3-12.

Arreola, H. J. 1996. Contribución al conocimiento de las cactáceas de Lagos de Moreno y Ojuelos de Jalisco, México. Tesis de licenciatura. Escuela Nacional de Estudios Profesionales Iztacala. Facultad de Biología, Universidad Nacional Autónoma de México. México, D.F. 149 pp.

Cervantes, N. 1992. La familia Malvaceae en el estado de Jalisco. Colección Flora de Jalisco 3: $1-393$.

Cronquist, A. 1981. An integrated system of classification of flowering plants. Columbia University Press. Nueva York. 1262 pp.

Curiel, A. 1998. Sistema productivo forestal: Descripción del sector forestal. Ordenamiento ecológico territorial del estado de Jalisco. Centro Universitario de Ciencias Biológicas y Agropecuarias. Universidad de Guadalajara. Guadalajara. 39 pp.

Challenger, A. 1998. Utilización y conservación de los ecosistemas terrestres de México: pasado, presente y futuro. Comisión Nacional para el Conocimiento y Uso de la Biodiversidad, Instituto de Biología, Universidad Nacional Autónoma de México, Agrupación Sierra Madre, S.C. México, D.F. pp. 617-724.

Dahlgren, R. M. T., H. T. Clifford y P. F Yeo. 1985. The families of monocotyledons; structure, evolution and taxonomy. Springer-Verlag. Berlín, Heidelberg, Nueva York, Tokio. $501 \mathrm{pp}$.

García, E. 1973. Modificaciones al sistema de clasificación climática de Köppen. 2a. ed. Instituto de Geografía. Universidad Nacional Autónoma de México. México, D.F. $217 \mathrm{pp}$.

Garcia, L. A. 2003. Listado florístico del rancho Las Papas de Arriba, municipio de Ojuelos de Jalisco, Jalisco, México. Tesis de licenciatura en Biología. Centro Universitario de Ciencias Biológicas y Agropecuarias, Universidad de Guadalajara. Guadalajara. $66 \mathrm{pp}$.

Garcia, L. A., O. Vargas y M. Harker. 2004. Nota sobre la presencia de Nierembergia angustifolia (Solanaceae) en Jalisco, México. Acta Bot. Mex. 67: 43-48.

González, A., M. E. Riojas-López y H. J. Arreola. 2001. El género Opuntia en Jalisco (Guía de campo). Universidad de Guadalajara y Comisión Nacional para el Conocimiento y Uso de la Biodiversidad. Guadalajara. 135 pp. 
González, L. M. 1986. Contribución al conocimiento del género Quercus (Fagaceae) en el estado de Jalisco. Colección Flora de Jalisco, Instituto de Botánica, Universidad de Guadalajara. Zapopan. 240 pp.

Harker, M., L. A. Garcia y R. Ramírez. 2005. Catálogo de plantas vasculares del municipio de Encarnación de Díaz, Jalisco, México. Ibugana 12(1): 3-16.

Jones, S. B. Jr. 1988. Sistemática Vegetal. McGraw-Hill. México, D.F. pp. 54-55.

Krebs, C. J. 1999. Ecological methodology. 2a. ed. Addison Wesley \& Benjamin Cummings. Menlo Park. 620 pp.

Lot, A. y F. Chiang (comps.). 1986. Manual de herbario: Administración y manejo de colecciones, técnicas de recolección y preparación de ejemplares botánicos. Instituto de Biología. Universidad Nacional Autónoma de México. Consejo Nacional de la Flora de México, A.C. México, D.F. 142 pp.

McVaugh, R. 1972. Botanical exploration in Nueva Galicia, Mexico. Contr. Univ. Mich. Herb. 9(3): 205-357.

McVaugh, R. 1983. Gramineae. Flora Novo-Galiciana 14: 1-436 .

McVaugh, R. 1984. Compositae. Flora Novo-Galiciana 12: 1-1157.

McVaugh, R. 1985. Orchidaceae. Flora Novo-Galiciana 16: 1-363.

McVaugh, R. 1987. Leguminosae. Flora Novo-Galiciana 5: 1-786.

McVaugh, R. 1989. Bromeliaceae to Dioscoreaceae. Flora Novo-Galiciana 15: 1-398.

McVaugh, R. 1993. Limnocharitaceae to Typhaceae. Flora Novo-Galiciana 13: 1-480.

McVaugh, R. 2001. Ochnaceae to Loasaceae. Flora Novo-Galiciana 3: 1-751.

Mickel, J. T. 1992. Gymnosperms and pteridophytes. Flora Novo-Galiciana 17: 1-467.

Noss, R. F. 1994. Cows and conservation biology. Conserv. Biol. 8: 613-616.

Paoletti, M. G., D. Pimentel, B. R. Stinner y D. Stinner. 1992. Agroecosystem biodiversity: matching production and conservation biology. Agric. Ecosyst. Environ. 40: 3-23.

Pinkava, D. J. 1984. Vegetation and flora of the Bolsón of Cuatro Ciénegas Region, Coahuila, México: IV. Summary, endemism and corrected catalogue. J. Ariz. - Nev. Acad. Sci. 19: 23-47.

Rabinowitz, D., S. Cairns y T. Dillon. 1986. Seven forms of rarity and their frequency in the flora of the British Isles. In: Soulé, M. E. (ed.). Conservation Biology. The science of scarcity and diversity. Sinauer Assoc. Inc. Sunderland. pp. 182-204.

Reyes-Agüero, J. A., F. González M. y J. D. García P. 1996. Flora vascular de la Sierra Monte Grande, municipio de Charcas, San Luis Potosí, México. Bol. Soc. Bot. Méx. 58: 31-42.

Riojas-López, M. E. y E. Mellink. 2005. Potential for biological conservation in manmodified semiarid habitats in northeastern Jalisco, Mexico. Biodivers. and Conser. 14: 2251-2263.

Rzedowski, G. C. de. 1960. Notas sobre la flora y la vegetación del estado de San Luis Potosí. VII. Vegetación en el valle de San Luis Potosí. Acta Cient. Potos. 4: 5-112.

Rzedowski, G. C. de, J. Rzedowski y colaboradores. 2001. Flora fanerogámica del Valle de México. 2a ed. Instituto de Ecología, A.C. y Comisión Nacional para el Conocimiento y Uso de la Biodiversidad. Pátzcuaro. 1406 pp. 
Rzedowski, J. 1972. Contribuciones a la fitogeografía, florística e histórica de México. III. Algunas tendencias en la distribución geográfica de las Compositae mexicanas. Ciencia, Méx. 27(4-5): 123-132.

Rzedowski, J. 1975. An ecological and phytogeographical analysis of the grasslands of Mexico. Taxon 24: 67-80.

Rzedowski, J. 1978. Vegetación de México. Ed. Limusa. México, D.F. 432 pp.

Rzedowski, J. y G. C. de Rzedowski. 1995. Los pastizales calcifilos del estado de Guanajuato. Flora del Bajío y Regiones Adyacentes. Fascículo Complementario IX: 1-19.

Rzedowski, J. y R. McVaugh. 1966. Vegetación de Nueva Galicia. Contr. Univ. Mich. Herb. 9: $1-123$.

Santana, F., H. J. Arreola y L. Scheinvar. 1987. Guía de excursión botánica a Lagos de Moreno y Ojuelos. Guías de excursiones botánicas en México. Soc. Bot. Méx. 8: 40-69.

Vargas, O., M. Cedano y L. Hernández. 2002. Catálogo de los trabajos botánicos en Jalisco. Scientia-CUCBA 4(2): 151-172.

Vargas, O., M. Martínez y P. Dávila. 1998. El género Physalis (Solanaceae) en el estado de Jalisco. Bol. Inst. Bot. 5: 395-401.

Villarreal, J. A. 1994. Flora vascular de la Sierra de la Paila, Coahuila, México. Sida 16(1): 109-138.

Villaseñor, J. L. 1993. La familia Asteraceae en México. Rev. Soc. Mex. Hist. Nat. Vol. Esp. (44): $117-124$.

Villaseñor, J. L. 2001. Catálogo de autores de plantas vasculares de México. Instituto de Biología, Universidad Nacional Autónoma de México y Comisión Nacional para el Conocimiento y Uso de la Biodiversidad. México, D.F. 40 pp.

Villaseñor, J. L. y F. J. Espinosa. 1998. Catálogo de malezas de México. Universidad Nacional Autónoma de México. Consejo Nacional Fitosanitario y Fondo de Cultura Económica. México, D.F. 449 pp.

Walter, K. S. y H. J. Gillett (eds.) 1998. IUCN red list of threatened plants. Compiled by the World Conservation Monitoring Centre. International Union for the Conservation of Nature. Gland y Cambridge. 862 pp. 


\section{APÉNDICE}

Catálogo florístico del rancho Las Papas de Arriba, municipio de Ojuelos de Jalisco, Jalisco, México.

Las siglas de los colectores: Pablo Carrillo Reyes (PCR), Luz Adriana Garcia Rubio (LAGR), Adriana González Durán (AGD), Mollie Harker (MH) y Verónica Rosas Espinoza (VRE). Formas de vida: arbórea (Ab), arbustiva (Ar), herbácea anual (Ha), herbácea perenne (Hp), crasicaule globosa (Cg), epífita (Ep) y parásita (Ps). Los hábitats de recolecta: matorral xerófilo crasicaule (MX), pastizal (P), cultivo maduro de nopal tunero (CM), cultivo joven de nopal tunero (CJ). La letra que sigue a cada hábitat hace referencia a la abundancia relativa de la especie por hábitat: escasa (e), frecuente (f) y abundante (a). Categoría de protección según la NOM 059-Ecol, 2001- amenazada (A), sujeta a protección especial (Pr); y según la IUCN 1998- rara (R). Las especies que se documentan por primera vez para Jalisco: se señalan con *.

\section{Filicopsida}

\section{Pteridophyta}

Adiantaceae

Cheilanthes allosuroides Mett., PCR 902, Hp, MX e

Cheilanthes bonariensis (Willd.) Proctor, PCR 804, Hp, MX f

Cheilanthes kaulfussii Kunze, LAGR 440, PCR 907, Hp, MX f

Cheilanthes sinuata (Sw.) Domin, LAGR 1036, Hp, MX f

Azollaceae

Azolla mexicana C. Presl, LAGR 1045A, Ha, MX e

Marsileaceae

Marsilea mollis B.L. Rob. \& Fernald, LAGR 241, Hp, P a

Marsilea sp., LAGR 216, 379, PCR 1026, 1028, Hp, P a

Polypodiaceae

Pellaea cordifolia (Sessé \& Moc.) A.R. Sm., LAGR 859, 1039, PCR 908, Hp, MXe

Phlebodium araneosum (M. Martens \& Galeotti) Mickel \& Beitel, PCR 1052, Hp, MX e

Phlebodium sp, MH 1242, Hp, MX e

Polypodium thyssanolepis A. Braun ex Klotzsch, LAGR 861, 1037, Hp, MX f

\section{Lycopodiopsida}

Selaginellaceae

Selaginella lepidophylla (Hook. \& Grev.) Spring in Mart., PCR 1062, Hp, MX a

Selaginella sartorii Hieron., PCR 922, Hp, MX e 


\section{Magnoliopsida}

\section{Magnoliophyta}

Acanthaceae

Dyschoriste microphylla (Cav.) Kuntze, PCR 831, 968, 1033, Hp, P f, CM e, CJ e

Stenandrium dulce (Cav.) Nees, LAGR 463, PCR 837, 1008, s.n., Hp, CJ e

Amaranthaceae

Amaranthus hybridus L., LAGR 392, 395, PCR 961, Ha, P f, CM e, CJ a

Gomphrena nitida Rothr., PCR 1065, Ha, MX e, P f, CM f, CJ e

Guilleminea densa Moq. var. densa, PCR 878, 1023, s.n., Hp, P f, CM f, CJ e

Anacardiaceae

Schinus molle L., PCR 1044, Ab, CM e

Apiaceae

Eryngium cymosum Delar., LAGR 309, PCR 953, 1027, Hp, MX e, P a, CM f, CJ a

Prionosciadium thapsoides (DC.) Mathias, MH 1219, Hp, MX e

Asclepiadaceae

Asclepias linaria Cav., PCR 648, Ar, MX a, CM e, CJ e

Matelea decumbens W.D. Stevens, PCR s.n., LAGR s.n., Ha, MX e, IUCN R

Asteraceae

Adenophyllum porophyllum (Cav.) Hemsl., MH 1308, Ha, CJ e

Ageratina brevipes (DC.) R.M. King \& H. Rob., MH 1336, Ar, MX f

Ageratina calaminthifolia (Kunth) R.M. King \& H. Rob., MH 1289, Ar, MX e

Ageratina petiolaris (DC.) R.M. King \& H. Rob., LAGR 1032, Ar, CM e, *

Ageratina robinsoniana (Greene) B.L. Turner, MH 1340, Ar, MX e

Ageratum corymbosum Zuccagni, MH 1284, Ar, MX e

Ambrosia canescens A. Gray, PCR 997, Hp, CM e

Aphanostephus ramosissimus DC. var. ramosissimus, MH 1232, Ha, MX e, P e, CM f, CJ a Artemisia klotzschiana Besser, MH 1369, Ha, P e, CM e

Aster subulatus Michx., MH 1277, Ha, P e

Baccharis occidentalis S.F. Blake, MH 1170, Hp, MX e

Baccharis pteronioides DC., MH s.n., Ar, MX e, P e, CM f, CJ e

Baccharis salicifolia (Ruiz \& Pav.) Pers., MH 1372, Ar, CM e

Baccharis sulcata DC., MH 1337, Ar, MXe, CM e

Bahia glandulosa Greenm., MH 1324, Ha, CJ e

Bahia schaffneri S.Watson var. schaffneri, MH 1309, Ha, P e, CJ e, *

Barkleyanthus salicifolius (Kunth) H. Rob. \& Brettell, MH 1165, Ar, MX e

Bidens ferulifolia (Jacq.) DC., MH 1344, Ha, MX e, P f, CM e, CJ a

Bidens odorata Cav., MH 1333, Ha, MX e, Pe, CJ f

Brickellia eupatorioides (L.) Shinners var. chlorolepis (Wooton \& Standl.) B.L. Turner, MH

1266, LAGR 854, Hp, Mx e, CM e, CJ f 
Brickellia secundiflora (Lag.) A. Gray var. secundiflora, MH 1429, Ar, CJ e

Brickellia secundiflora (Lag.) A. Gray var. nepetifolia (Kunth) B.L. Rob., MH 1341, Ar, MX e

Brickellia veronicifolia (Kunth) A. Gray, MH 1174, Ar, MX f, CM e

Chaetopappa ericoides (Torr.) G.L. Nesom, MH 1171, Hp, MX e, CM e, CJ e, *

Coreopsis rudis (Benth.) Hemsl., MH 1338, Ar, MX e

Cosmos parviflorus (Jacq.) Pers., MH 1315, Ha, P e, CJ f

Dahlia coccinea Cav., MH 1256, Hp, MX f

Dyssodia papposa (Vent.) Hitchc., MH 1305, Ha, MX f, P a, CM f, CJ a

Dyssodia pinnata (Cav.) B.L. Rob., MH 1310, Hp, CM e, CJ e

Erigeron janivultus G.L. Nesom, $\mathrm{MH}$ 1334, Hp, MX e

Galinsoga parviflora Cav., MH 1279, Ha, MX e, CM e, CJ f

Galinsoga quadriradiata Ruiz \& Pav., MH 1328, Ha, CJ e

Gamochaeta sphacelata (Kunth) Cabrera, MH 1164, Ha, CM e, CJ e

Gutierrezia seriocarpa (A. Gray) M.A. Lane, MH 1267, Hp, P e, CM e

Helenium mexicanum Kunth, MH 1229, Ha, MX e, P e, CJ e

Heterosperma pinnatum Cav., MH 1280, Ha, MX e, CM a, CJ a

Hieracium abscissum Less., MH 1212, Hp, CJ e

Isocoma hartwegii (A. Gray) Greene, MH 1214, Ar, P a, CM a, CJ e

Laennecia filaginoides (DC.) G.L. Nesom, MH 1312, Ha, MX e, P e, CJ f

Laennecia microglossa (S.F. Blake) G.L. Nesom, MH s.n., Ha, P e

Laennecia sophiifolia (Kunth) G.L. Nesom, MH 1369, Ha, MX e, P e, CM a, CJ a

Machaeranthera pinnatifida (Hook.) Shinners var. pinnatifida, MH 1248, Hp, MX e, CM e Melampodium strigosum Stuessy, MH 1300, Ha, CJ e, *

Montanoa leucantha (Lag. \& Segura) S.F. Blake ssp. leucantha, MH 1281, Ar, MX f

Perymenium mendezii DC. var. mendezii, MH 1255, Ar, MX a, CM e

Pinaropappus roseus (Less.) Less. var. roseus, MH 1257, Hp, MX e, P e, CM e, CJ e

Piqueria trinervia Cav., MH 1176, Ar, MX a, P e, CM a, CJ e

Pittocaulon praecox (Cav.) H. Rob. \& Brettell, MH 1179, Ar, MX a

Psacalium sinuatum (Cerv.) H. Rob. \& Brettell, MH 1276, Hp, MX e, P a, CM e, CJ e

Pseudognaphalium canescens (DC.) Anderb., MH 1275, Hp, P f, CM f

Pseudognaphalium conoideum (Kunth) Anderb., MH 1270, Ha, CJ e, *

Pseudognaphalium liebmannii (Sch. Bip. ex Klatt) Anderb. var. monticola (McVaugh)

Anderb., MH 1271, Ha, CM e

Pseudognaphalium semiamplexicaule (DC.) Anderb., MH 1304, Hp, P e, CM f, CJ e

Pseudognaphalium semilanatum (DC.) Anderb., MH 1293, Hp, CM f

Pseudognaphalium viscosum (Kunth) Anderb., MH 1297, Ha, CJ f

Psilactis asteroides A. Gray, MH 1278, Ha, Pe, CJ e

Roldana heracleifolia (Hemsl.) H. Rob. \& Brettell, MH 1318, Hp, CM e

Schkuhria pinnata (Lam.) Kuntze var. virgata (Llave) Heiser, MH 1250, Ha, MX e, P a, CM

e, CJ a

Schkuhria schkuhrioides (Link \& Otto) Thell., MH 1283, Ha, MX e, P a, CJ a

Simsia amplexicaulis (Cav.) Pers., MH 1313, Ha, CJ f

Soliva anthemifolia (Juss.) R. Br. ex Less., MH 1175, Ha, P a 
Sonchus oleraceus L., MH 1298, Ha, CJ e

Stevia lucida Lag. var. lucida, MH 1339, Hp, MX f

Stevia micrantha B.L. Rob., MH 1319, Ha, CM e

Stevia porphyrea McVaugh, MH 1314, Hp, MX e, P e, CM e, CJ e

Stevia salicifolia Cav. var. salicifolia, $\mathrm{MH}$ 1178, Ar, MX a, CM e

Stevia serrata Cav. var. arguta B.L. Rob., MH 1286, Hp, MX e, P f, CM e, CJ f

Tagetes filifolia Lag., MH 1301, Ha, MX f, P e, CJ a

Tagetes lucida Cav., MH 1349, Hp, CJ e

Tagetes lunulata Ortega, MH 1288, Ha, MX f, CJ f

Tagetes micrantha Cav., MH 1329, Ha, MX f, CJ e

Tithonia tubiformis (Jacq.) Cass., MH 1325, Ha, CJ e

Tridax balbisioides (Kunth) A. Gray, MH 1285, Ha, MX f

Tridax petrophila B.L. Rob. \& Greenm., MH 1330, Hp, MX e, CM e

Verbesina mollis Kunth, MH 1282, Ar, MX e

Zaluzania augusta (Lag.) Sch. Bip., MH 1317, LAGR 867, Ar, MX e, CM e

Zinnia angustifolia Kunth var. angustifolia, MH 1331, Hp, MX a

Boraginaceae

Cryptantha albida (Kunth) I.M. Johnst., PCR 876, 986, 1000, Hp, CM e

Brassicaceae

Brassica campestris L., LAGR 225, 234, PCR 832, 955, Ha, CJ a

Eruca sativa Mill., LAGR 408, PCR 872, Ha, CM e

Lepidium virginicum L., LAGR 249, 453, PCR 870, Ha, MX e, P e, CM a, CJ f

Mancoa mexicana Gilg \& Muschl., MH 1238, Ha, CJ e, *

Raphanus raphanistrum L. \& Muschl., LAGR 247, 410, PCR 983, MH 1238, Ha, CM e

Rorippa mexicana (Moc. \& Sessé) Standl. \& Steyerm., PCR 874, 1061, MH 1227, Hp, MX

e, $\mathrm{CM} \mathrm{f}$

Burseraceae

Bursera fagaroides (Kunth) Engl., MH 1364, Ab, MX e

Cactaceae

Coryphantha cornifera (Engelm.) Lem., (observado), Cg, MX f, P f, CM e, CJ e

Coryphantha ottonis (Pfeiff.) Lem., AGD 136, Cg, P e

Echinocereus pulchellus (Mart.) K. Schum., AGD 137, Cg, P e

Ferocactus histrix (DC.) G.E. Linds., (observado), Cg, MX a, P e, NOM-059 Pr

Ferocactus latispinus (Haw.) Britton \& Rose, (observado), Cg, MX e, CM e

Mammillaria fuscohamata Backeb., PCR 653, Cg, P f, CM e, CJ e

Mammillaria gilensis Boed., PCR 807, Cg, MX f

Mammillaria uncinata Zucc., LAGR 1047, Cg, MX f, P e, CM e, CJ f

Opuntia albicarpa Scheinvar cv Burrona, LAGR 866, Ar, CM a

Opuntia chavena Griffiths, AGD 128, Ab, MX e, P e

Opuntia cochinera Griffiths, AGD 114, Ar, MX e, P e 
Opuntia hyptiacantha F.A.C. Weber, AGD 115, Ab, MX e, P e

Opuntia joconostle F.A.C. Weber, AGD 141, Ar, MX f, P e

Opuntia lasiacantha Pfeiff., LAGR 205, Ar, MX e

Opuntia leucotricha DC., AGD 140, Ab, MX e

Opuntia megacantha Salm-Dyck cv Picochulo, LAGR (observada), Ar, CM a

Opuntia megacantha Salm-Dyck cv Torreoja, LAGR 865, Ar, CM a

Opuntia robusta H.L. Wendl., AGD 112, Ar, MX f, P e

Opuntia streptacantha Lem., AGD 127, 131, Ab, MX e, P e

Stenocactus ochoterenanus Tiegel, PCR 646, Cg, MX a

Callitrichaceae

Callitriche heterophylla Pursh, LAGR 437, 1046, PCR 912, 1056, Ha, MX e

Campanulaceae

Diastatea tenera (A. Gray) McVaugh, MH 1363, Ha, MX e

Lobelia berlandieri A. DC. var. seleriana (E. Wimmer) E. Wimmer, LAGR 490, 1053, PCR 650, 1051, Ha, MX f, *

Lobelia fenestralis Cav., PCR 947, Ha, CJ e

Triodanis biflora (Ruiz \& Pav.) Greene, LAGR 480, Ha, MX e

Caryophyllaceae

Arenaria bourgaei Hemsl., LAGR 496, PCR 996, 1015, 1017, 1020, MH 1225, Hp, P f

Cardionema ramosissima (Weinm.) A. Nelson \& J.F. Macbr., PCR 980, 1013, MH 1368, Hp, $\mathrm{P}$ e, $\mathrm{CM}$ a

Drymaria glandulosa Bartl., LAGR 292, PCR 669, Ha, CM e

Drymaria villosa Cham. \& Schltdl., PCR 1059, Ha, MX e

Paronychia mexicana Hemsl., PCR 910, Hp, MX e

Spergularia mexicana Hemsl., LAGR 24, 302, PCR 849, Hp, P e, *

Stellaria graminea L., PCR 1059A, Ha, MX e

Chenopodiaceae

Chenopodium graveolens Willd., LAGR 280, PCR 905, 952, 1037, Ha, P e, CM f, CJ a

Chenopodium murale L., LAGR 293, 306, 394, PCR 951, 979, 1010, Ha, MX e, CM e, CJ f

Cistaceae

Helianthemum patens Hemsl., LAGR 274, PCR 691, s.n., Hp, MX f

Helianthemum pugae Calderón, PCR 808, 1053, Hp, MX e

Clusiaceae

Hypericum philonotis Cham. \& Schltdl., LAGR 1042, Ha, MX f

Convolvulaceae

Dichondra argentea Willd., PCR 852, 945, Hp, MX f, P f, CM f, CJ f

Evolvulus alsinoides L., LAGR 449, PCR 779, 906, Hp, MX e, P f, CM e, CJ f 
Evolvulus sericeus Sw., LAGR 223, 265, PCR 942, Hp, P a, CJ f

Ipomoea capillacea (Kunth) G. Don, LAGR 21, 239, PCR 851, s.n., MH 1234, Hp, MX e, $\mathrm{P} \mathrm{f}$

Ipomoea emetica Choisy, LAGR 1345, Hp, MX e

Ipomoea lenis House, LAGR 230, 277, 290, PCR 862, Hp, MX f

Ipomoea purpurea (L.) Roth, LAGR s.n., Ha, MX e, CM e

Ipomoea stans Cav., LAGR 220, MH 1239, Hp, P e, CM f, CJ f

Ipomoea sp., LAGR s.n., PCR s.n., Ha, CJ e

Crassulaceae

Echeveria mucronata Schltdl., LAGR 500, PCR 1034, Hp, MX e

Tillaea aquatica L., PCR 1057, Ha, MX e, *

Villadia misera (Lindl.) R.T. Clausen, PCR 909, Hp, MX e

Cucurbitaceae

Cucurbita radicans Naudin, PCR 995, Ha, P e

Sicyos laciniatus L., PCR 985, Ha, CM e

Cuscutaceae

Cuscuta potosina W. Schaffn., LAGR 438, 451, PCR 1072, Ps, MX e

Euphorbiaceae

Acalypha infesta Poepp. \& Endl., PCR 957, Ha, CJ e

Euphorbia anychioides Boiss., LAGR 422, PCR 1064, Hp, MX f, P a, CM f, CJ a

Euphorbia dentata Michx., PCR 900, Ha, MX e

Euphorbia indivisa (Engelm.) Tidestr., LAGR 441, PCR 923,1063, Ha, MX f, P e

Euphorbia macropus (Klotzsch \& Garcke) Boiss., LAGR 255, 256, MH 1241, Hp, MX f, $\mathrm{CJ} \mathrm{f}$

Euphorbia nutans Lag., VRE 4, Ha, CJ e

Euphorbia radians Benth., LAGR 1033, PCR 654, 964, 970, Hp, CM f, CJ f

Euphorbia serpyllifolia Pers., LAGR 229, PCR 975, s.n., Ha, MX a, CM a

Euphorbia sphaerorhiza Benth., PCR 838, MH 1212, Hp, CJ e

Euphorbia stictospora Engelm., PCR 1018, Ha, P e

Jatropha dioica Cerv., LAGR 201, MH 1359, Ar, MX a

Fabaceae

Acacia schaffneri (S. Watson) F.J. Herm., PCR 656, 801, Ar, CM e

Astragalus hartwegii Benth., PCR 836, Hp, CJ e

Astragalus mollissimus Torr. var. irolanus (M.E. Jones) Barneby, PCR 965, Hp, P e, CM e,

CJ e

Astragalus sp., LAGR 491, Hp, P e

Calliandra humilis Benth. var. reticulata (A. Gray) L.D. Benson, LAGR 264, Hp, CJ e

Dalea bicolor Humb. \& Bonpl. ex Willd. var. bicolor, PCR 896, 1067, s.n., Ar, MX a, CM f

Dalea leporina (Aiton) Bullock, PCR 967, Ha, CM e 
Desmodium neomexicanum A. Gray, PCR 916, Ha, MX e Desmodium tortuosum (Sw.) DC., LAGR 1329, Hp, MX f Erythrina leptorhiza DC., MH 1244, Hp, MX e Eysenhardtia polystachya (Ortega) Sarg., LAGR 853, Ar, MX e Eysenhardtia punctata Pennell, PCR 857, Ar, MX e, CM e Indigofera miniata Ortega, PCR 846, Hp, MX e Indigofera montana Rose, LAGR 856, Hp, MX e Macroptilium gibbosifolium (Ortega) A. Delgado, LAGR 221, PCR 833, MH 1231, Hp, CM $\mathrm{e}, \mathrm{CJ} \mathrm{f}$

Mimosa aculeaticarpa Ortega, LAGR 477, MH 1220, Ar, MX f

Phaseolus polymorphus S. Watson, LAGR 650, Ha, MX e

Trifolium goniocarpum Lojac., LAGR 248, 401, PCR 847, Hp, P e, CM e

Zornia thymifolia Kunth, PCR s.n., LAGR 435, Hp, MX e

Fagaceae

Quercus eduardi Trel., PCR 682, Ab, MX e

Quercus grisea Liebm., PCR 647, 688, MH 1361, Ab, MX a

Quercus potosina Trel., PCR 869, MH 1362, Ab, MX a

Gentianaceae

Centaurium brachycalyx Standl. \& L.O. Williams, PCR 649, 690, Ha, MX e

Centaurium quitense (Kunth) B.L. Rob., LAGR 1052, Ha, MX e

Geraniaceae

Erodium cicutarium (L.) L' Hér., LAGR 245, 273, 308, PCR 877, Ha, MX e, CM e

Geranium seemannii Peyr., LAGR 863, Hp, CM e

Hydrophyllaceae

Nama origanifolium Kunth, LAGR 439, 470, 482, PCR 651, Hp, MX f

Lamiaceae

Marrubium vulgare L., LAGR 1059, Hp, CM e

Salvia axillaris Moc. \& Sessé, PCR 864, MH 1217, Hp, MX a

Salvia hirsuta Jacq., PCR 962, s.n., Ha, CJ e

Salvia reflexa Hornem., LAGR 210, 468, PCR 776, 1048, s.n., Ha, MX e

Stachys coccinea Jacq., PCR 897, Hp, MX e

Loganiaceae

Buddleja cordata Kunth, LAGR 415, PCR 978, Ab, CM f, CJ e

Buddleja scordioides Kunth, LAGR 530, PCR 800, Ar, CM e

Buddleja sessiliflora Kunth, LAGR 489, 1058, PCR 657, Ar, CM e

Lythraceae

Lythrum gracile Benth., PCR 826, 1066, Hp, MX e, CJ e 
Malpighiaceae

Aspicarpa hirtella Rich., LAGR 1326, Hp, MX e

Malvaceae

Anoda pubescens Schltdl., LAGR 651, Hp, MX e

Fuertesimalva jacens (S. Watson) Fryxell, LAGR 414, PCR 963, Hp, CM e, CJ e, *

Malva parviflora L., LAGR 235, PCR 956, Ha, CJ e

Sida abutifolia Mill., LAGR 652, Hp, MX e, P e

Sida linearis Cav., LAGR 228, 275, 421, s.n., Hp, MX e, P f, CM e, CJ f

Sphaeralcea angustifolia (Cav.) G. Don, PCR 936, s.n., Ar, CM e, CJ e

Nyctaginaceae

Mirabilis longiflora L., LAGR 281, PCR 856, Hp, MX e

Oxybaphus violaceus (L.) Choisy, PCR 899, Hp, MX e

Onagraceae

Gaura hexandra Ortega, PCR 950, MH 1215, Hp, CM e, CJ f

Lopezia trichota Schltdl., LAGR 288, Hp, MX e

Oenothera kunthiana (Spach) Munz, LAGR 214, 267, 461, PCR 981, 984, MH 1230, Hp, MX e, CM e, CJ e

Oenothera pubescens Willd. ex Spreng., LAGR 1055, PCR 825, 1011, Hp, P e, CJ f

Oenothera rosea L'Hér. ex Aiton, LAGR 402, PCR 871, Hp, CM f

Oxalidaceae

Oxalis corniculata L., LAGR 227, PCR 873, 949, MH 1216, Hp, CM e, CJ e

Oxalis decaphylla Kunth, LAGR 219, 231, MH 1245, Hp, P e, CM e, CJ a

Pedaliaceae

Proboscidea louisianica (Mill.) Thell., LAGR 653, Ha, P e

Phytolaccaceae

Phytolacca icosandra L., LAGR 391, PCR 655, 954, Hp, MX e, CM f, CJ e

Piperaceae

Peperomia campylotropa A.W. Hill, LAGR 208, MH 1240, Hp, MX f

Plantaginaceae

Plantago nivea Kunth, LAGR 215, 250, 266, PCR 822, Hp, MX a, CM a, CJ f

Plumbaginaceae

Plumbago pulchella Boiss., PCR 904, Hp, MX e

Polemoniaceae

Loeselia coerulea (Cav.) G. Don, LAGR 434, PCR 1071, Hp, MX e 
Loeselia mexicana (Lam.) Brand, PCR 924, Ar, MX f

Polygonaceae

Eriogonum wrightii Torr. ssp. wrightii, $\mathrm{MH} 1374, \mathrm{Ar}, \mathrm{CM}$ e, *

Polygonum aviculare L., LAGR 404, 864, Ha, P e

Polygonum mexicanum Small, LAGR 1043, Ha, MX e

Portulacaceae

Portulaca oleracea L., PCR 895, Ha, MX e

Portulaca pilosa L., PCR 933, 1014, Hp, P e, CJ e

Portulaca sp., PCR 1019, Ha, P e

Talinopsis frutescens A. Gray, PCR 866, Ar, MX f

Talinum napiforme DC., LAGR 237, PCR 917, MH 1245, Hp, MX e, CJ e

Rafflesiaceae

Pilostyles thurberi A. Gray, PCR 879, 918, Ps, MX e

Rosaceae

Prunus microphylla (Kunth) Hemsl., LAGR 232, MH 1237, Ar, CJ e, *

Prunus serotina Ehrh. ssp. capuli (Cav.) McVaugh, PCR 868, Ab, MX e

Rubiaceae

Bouvardia scabrida M. Martens \& Galeotti, LAGR 396, 469, PCR 934, Ar, MX f, CJ e

Bouvardia ternifolia (Cav.) Schltdl., LAGR 416, PCR 865, Ar, MX e, CM f

Crusea diversifolia (Kunth) W.R. Anderson, PCR 919, 946, 959, 1047, Ha, MX f, CM e, $\mathrm{CJ}$ e

Houstonia wrightii A. Gray, LAGR 403, PCR 875, 948, Hp, P e, CM e, CJ e

Spermacoce verticillata L., LAGR 271, PCR 1007, Hp, MX f, CM e, CJ e

Salicaceae

Salix humboldtiana Willd., PCR 778, 1036, Ab, P e

Sapindaceae

Dodonaea viscosa (L.) Jacq., LAGR 1044, PCR 652, Ar, MX a, CM e

Scrophulariaceae

Bacopa monnieri (L.) Pennell, PCR s.n., Hp, MX e, P f

Bacopa procumbens (Mill.) Greenm., LAGR 457, PCR 848, Hp, MX f, P f, CM f

Buchnera pusilla Kunth, PCR 1060, Ha, MX e

Castilleja lithospermoides Kunth, PCR 960, 1009, Hp, CJ e

Castilleja tenuiflora Benth., LAGR 420, PCR 921, 1050, Hp, MX f, CJ e

Linaria canadensis (L.) Dumort., LAGR 1034, Ha, MX e, *

Penstemon schaffneri (Hemsl.) Straw, LAGR 1038, PCR 858, 901, Hp, MX e

Stemodia durantifolia (L.) Sw., LAGR 426, 430, 1050, PCR 1054, Ha, MX f, CJ e 
Solanaceae

Bouchetia erecta DC., LAGR 218 A, 307, PCR 835, 958, 1024, Hp, P a, CJ a Jaltomata procumbens (Cav.) J.L. Gentry, LAGR 411, PCR 824, 943, Hp, CM e, CJ e Nicotiana glauca Graham, PCR 657A, Ar, P e, CM e

Nierembergia angustifolia Kunth, LAGR 298, 487, 492, Hp, P e, IUCN R

Petunia parviflora Juss., LAGR 303, 400, 485, PCR 1042, Ha, P f, CJ f

Physalis chenopodifolia Lam., LAGR 1040, PCR 973, Hp, P e, CM e

Physalis glutinosa Schtldl., PCR 693, 855, Hp, MX e, IUCN R

Physalis hastatula Waterf., PCR 1002, MH 1213, 1371, Hp, CJ e

Physalis patula Mill., LAGR 233, 452, PCR 823, Ha, CM f, CJ a

Physalis waterfallii O. Vargas, M. Martínez \& Dávila, PCR 969, Hp, CM e

Solanum americanum Mill., PCR 971, 1003, Ha, CM e, CJ e

Solanum angustifolium Mill., LAGR 244, PCR 932, 1035, Ha, P a, CJ e

Solanum dasyadenium Bitter, LAGR 412, PCR 1001, 1006, Ha, CM e, CJ e

Solanum elaeagnifolium Cav., PCR 850, Hp, CM f

Solanum pubigerum Dunal, LAGR 407, PCR 974, Hp, CM e

Solanum rostratum Dunal, PCR 976, Hp, P e, CJ e

Solanum stoloniferum Schtdl., PCR 867, Hp, MX e

Verbenaceae

Phyla nodiflora (L.) Greene, LAGR 297, Hp, P e

Priva grandiflora (Ortega) Moldenke, LAGR 661, MH 1261, Hp, P e, CM e, CJ e

Verbena bipinnatifida Nutt., PCR 828, Hp, CJ f

Verbena gracilis Desf., LAGR 240, 272, PCR 1025, MH 1252, 1260, Hp, P f, CJ e

Verbena teucriifolia M. Martens \& Galeotti, LAGR 429, Ha, MX e, Pe, CM e

Violaceae

Hybanthus verticillatus (Ortega) Baill., VRE 22, Hp, CJ e

Viola barroetana W. Schaffn., LAGR 226, MH 1236, Hp, P f, CJ a

Vitaceae

Cissus sicyoides L., LAGR 860, PCR 777, Hp, MX e

\section{Liliopsida}

Agavaceae

Agave filifera Salm-Dyck, LAGR 202, Hp, MX e

Polianthes geminiflora (Lex.) Rose, LAGR 654, Hp, MX e

Yucca decipiens Trel., LAGR 203, 204, Ab, MX e

Alliaceae

Allium scaposum Benth., LAGR 253, MH 1222, Hp, Mx e, P e

Milla biflora Cav., MH 1292, Hp, MX e, P f, CM e, CJ a 
Harker et al.: Composición florística del rancho Las Papas de Arriba, Jalisco, México

Anthericaceae

Echeandia flavescens (Schult. \& Schult. f.) Cruden, LAGR 224, 254, 305, PCR 859, Hp, MX e, CJ e

Bromeliaceae

Tillandsia recurvata (L.) L., LAGR 445, 1051, PCR 672, Ep, MX a

Tillandsia tortilis Klotzsch ex Baker, LAGR 862, 998, PCR 673, Ep, MX e

Calochortaceae

Calochortus barbatus (Kunth) J.H. Painter, LAGR 206, PCR 834, 839, Hp, MX f, P f, CJ a

Commelinaceae

Callisia insignis C.B. Clarke, PCR 1070, Hp, MX e

Commelina dianthifolia DC., LAGR 251, 276, 406, 450, PCR 853, 911, 966, Hp, MX e,

$\mathrm{CM}$ e

Tradescantia crassifolia Cav., LAGR 220, 252, PCR 854, Hp, MX f

Tripogandra purpurascens (S. Schauer) Handlos, LAGR 275, 507, Ha, MX f, CM e

Cyperaceae

Bulbostylis juncoides (Vahl) Kük., LAGR 213, 270, PCR 926, 1046, Hp, MX a

Cyperus calderoniae S. González, LAGR 209, 212, PCR 863, 925, Hp, MX e, CM e

Cyperus esculentus L., LAGR 262A, PCR 982, Hp, CM e

Cyperus flavescens L. var. piceus (Liebm.) Fernald, PCR 915, Ha, MX f

Cyperus reflexus Vahl, LAGR 1054, PCR 1064, Hp, MX e

Cyperus seslerioides Kunth, LAGR 207, PCR 827, MH 1233, Hp, MX a, CJ a

Eleocharis acicularis (L.) Roem. \& Schult., PCR 861, MH 1226, Hp, P f

Eleocharis macrostachya Britton, PCR 860, 972, MH 1221, Hp, MX a, CM e

Eleocharis sp., MH 1225, Ha, P e

Iridaceae

Nemastylis tenuis (Herb.) Benth. ex Baker, LAGR 238, MH 1223, Hp, MX f, Pa, CM f, CJ a Sisyrinchium cernuum (E.P. Bicknell) Kearney, PCR 1055, Ha, MX f

Sisyrinchium tenuifolium Humb. \& Bonpl. ex Willd., LAGR 222, 254, PCR 829, MH 1235,

$\mathrm{Hp}, \mathrm{MX}$ f, P a, CM f, CJ a

Juncaceae

Juncus microcephalus Kunth, LAGR 1048, PCR 1068, MH 1375, Hp, MX e

Lemnaceae

Lemna gibba L., LAGR 1045, Ha, MX e

Lilaeaceae

Lilaea scilloides (Poir.) Hauman, PCR 1022, Ha, Pe 
Liliaceae

Zephyranthes concolor (Lindl.) Benth. \& Hook., PCR 806, Hp, MX e

Zephyranthes fosteri Traub, LAGR 494, 495, 1031, PCR 803, Hp, MX f, P f, CJ f

Nolinaceae

Dasylirion acrotriche (Schiede) Zucc., LAGR 198, 199, 200, PCR 802, 809, Ar, MX a, NOM-059 A

Poaceae

Aeopogon cenchroides Humb. \& Bonpl. ex Willd., LAGR 471, 478, PCR 927, 928, 1075, $\mathrm{Hp}, \mathrm{MX}$ e

Aristida divaricata Humb. \& Bonpl. ex Willd., LAGR 284, PCR 994, Hp, MX f, P a, CM f, CJ a

Aristida schiedeana Trin. \& Rupr., LAGR 285, 428, Hp, MX e

Bothriochloa barbinodis (Lag.) Herter var. barbinodis, LAGR 283, 399, PCR 1005, 1079, $\mathrm{Hp}, \mathrm{MX}$ e, CM f

Bouteloua chondrosioides (Kunth) Benth. ex S. Watson, PCR 929, 931, Hp, MX e, P e

Bouteloua curtipendula (Michx.) Torr. in Marcy, LAGR 287, PCR 935, 1012, Hp, MX e, CJ f

Bouteloua gracilis (Kunth) Lag. ex Steud. var. gracilis, LAGR 381, PCR 845, Hp, MX f, P a, CM f, CJ a

Bouteloua hirsuta Lag., LAGR 282, PCR 991, Hp, MX e, P e, CM e, CJ e

Bouteloua scorpioides Lag., LAGR 304, Hp, P f, CM e, CJ e

Bouteloua simplex Lag., LAGR 263, 279, 301, PCR 989, 1031, Ha, MX f, P a, CM f, CJ f

Brachiaria meziana Hitchc., PCR 842, Hp, MX e

Bromus carinatus Hook. \& Arn., LAGR 291, Hp, CM e

Buchloe dactyloides (Nutt.) Engelm., PCR 841, Hp, MX e, P f

Chloris submutica Kunth, PCR 1077, Hp, MX e, P e

Chloris virgata Sw., LAGR 300, PCR 937, 1032, Ha, MX e, Pe, CM e, CJ f

Cynodon dactylon (L.) Pers., PCR 844, Hp, MX f

Digitaria biformis Willd., LAGR 419, s.n., Hp, P f, CM e

Echinochloa crus-galli (L.) P. Beauv., PCR 1073, Ha, MX e

Eleusine multiflora Hochst. ex A. Rich., LAGR 380, 459, PCR 1043, Ha, P e, CM e, CJ e

Elyonurus barbiculmis Hack. in DC., LAGR 398, Hp, CJ e

Eragrostis curvula (Schrad.) Nees, PCR 830, Hp, CJ e

Eragrostis intermedia Hitchc., LAGR 259, 382, 397, PCR 1080, Hp, MX f, CM f, CJ e

Eragrostis mexicana (Hornem.) Link, LAGR 243, 262, 278, 299, 456, PCR 938, 939, 990,

$\mathrm{Ha}, \mathrm{MX}$ e, P e, CM f, CJ e

Eragrostis tephrosanthos Schult. in Roem. \& Schult., PCR 998, Ha, P e, CM e

Hordeum vulgare L., LAGR 258, Ha, CM e

Leptochloa dubia (Kunth) Nees, LAGR 290, Hp, CM e

Leptochloa fascicularis (Lam.) A. Gray, LAGR 294, 420, Ha, CM e

Lycurus phleoides Kunth, LAGR 261, PCR 930, 941, 988, 1004, Hp, MX a, P e, CM a, CJ a

Microchloa kunthii Desv., PCR s.n., Hp, P e 
Muhlenbergia implicata (Kunth) Kunth, LAGR 484, Ha, MX e

Muhlenbergia peruviana (P. Beauv.) Steud., LAGR 431, 483, PCR 1074, Ha, MX e, P e Muhlenbergia pubescens (Kunth) Hitchc., LAGR 286, 436, Hp, MX e, CM e

Muhlenbergia repens (J. Presl) Hitchc., PCR 1030, 1041, s.n., Hp, P a, CM f

Muhlenbergia rigida (Benth.) Hitchc., LAGR 424, 481, PCR 940, 987, 1016, Hp, MX f, P f, $\mathrm{CM}$ e, CJ a

Muhlenbergia utilis (Torr.) Hitchc., PCR s.n., Hp, P f

Nassella mucronata (Kunth) R.W. Pohl, LAGR 260, 481, PCR 993, Hp, MX f, Pe, CM e

Panicum vaseyanum Scribn. ex Beal, LAGR 296, 418, PCR 997, Ha, P f

Piptochaetium fimbriatum (Kunth) Hitchc., LAGR 466, Hp, MX e

Rhynchelytrum repens (Willd.) C.E. Hubb., LAGR 269, Hp, MX a, CM e

Schizachyrium sanguineum (Retz.) Alston, PCR 1078, Hp, MX e

Setaria parviflora (Poir.) Kerguélen, LAGR 472, Hp, MX e, CM e

Setaria viridis (L.) P. Beauv., LAGR 423, 427, PCR 944, Ha, MX e, CJ f

Sorghum halepense (L.) Pers., LAGR 486, Hp, P e

Sporobolus pyramidatus (Lam.) Hitchc., LAGR 268, PCR 843, 1029, Hp, MX f, P f

Trachypogon secundus (J. Presl) Scribn., LAGR 310, Hp, MX e

Tripogon spicatus (Nees) Ekman, PCR 1076, Hp, MX f

Pontederiaceae

Heteranthera rotundifolia (Kunth) Griseb., PCR 914, Ha, MX e

Potamogetonaceae

Potamogeton diversifolius Raf., LAGR 1041, PCR 689, 913, Hp, MX e 
